\title{
Microstructure and Rheological Properties of Semi-Solid 7075 Slurries Using SEED Rheocasting Process
}

\author{
Amir Bolouri ${ }^{1, a}$, Qinfu Zhao ${ }^{2, b}$, Pascal Côté ${ }^{3, \mathrm{c}}$ and X.-Grant Chen ${ }^{2, \mathrm{~d}^{*}}$ \\ ${ }^{1}$ Mechanical and Automotive Engineering, University of the West of England, Bristol, UK, \\ BS161QY and formerly Department of Applied Science, University of Quebec at Chicoutimi. \\ ${ }^{2}$ Department of Applied Science, University of Quebec at Chicoutimi, \\ 555, boulevard de l'Universite, Saguenay (Quebec), Canada G7H 2B1 \\ ${ }^{3}$ Société des Technologies de l'Aluminium du Saguenay Inc. (STAS), \\ 1846, rue des Outardes, Saguenay (Quebec), Canada G7K 1H1 \\ a amir.bolouri@uwe.ac.uk, ${ }^{\mathrm{b}}$ qinfu.zhao1@uqac.ca, ${ }^{\mathrm{c}}$ cote.pascal@stas.com, \\ dxgrant_chen@uqac.ca (corresponding author)
}

Keywords: SEED rheocasting process, Semi-solid forming, 7075 aluminum alloy, Grain refinement, Microstructure, Rheological properties.

\begin{abstract}
The SEED rheocasting process was used to produce semisolid slurries of high strength 7075 aluminum wrought alloys. The effects of the SEED processing parameters on the microstructure of semisolid slurries were studied. The impact of grain refinement on the grain morphology and size was investigated. The rheological properties of semisolid 7075 alloys were characterized at different solid fractions using a parallel plate compression viscometer. Results indicated that the grain refinement could greatly improve the globularity of $\alpha$-Al grains and rheoformability. The relationships between viscosity and shear rate at different solid fractions in the transient state for both unrefined and refined semisolid slurries were evaluated and discussed.
\end{abstract}

\section{Introduction}

There is a strong demand to semisolid forming of high strength 7075 aluminum components, which are currently manufactured by costly machining process. For semisolid forming of 7075 alloys, thixoforming has been majorly used that involves reheating of extruded billet into the semisolid state followed by die casting process [1-3]. The main issue with thixoforming process is the cost associated with an intermediate pre-fabricated billet, which makes the overall process economically impractical. Rheocasting is a reliable semisolid processing that the semisolid slurry is produced directly from liquid phase [4-5]. In the rheocasting process, the liquid metal is stirred while it is simultaneously cooled down to obtain the desired processing temperature corresponding to a predetermined solid faction. The stirring results in the formation of fine and globular grain structure [6]. The SEED process is one of few commercially available rheocasting technologies to produce high quality semisolid aluminum slurries in the foundry industry [7].

It has been reported that the transient rheological behavior (viscosity vs shear rate) of semisolid slurries strongly depends on the solid fraction [8-9]. In a typical industrial situation of semisolid casting, a semisolid slurry is injected into a die cavity where the die filling takes place in less than one second [10-11]. During such short time, the shearing of the semisolid slurry rapidly occurs and the viscosity of semisolid slurry will be changed significantly from several hundred Pa.s (being solid-like) to a few Pa.s (being liquid-like). The measurement on the rapid shear change in this magnitude is beyond the capacity of the conventional rotational rheometers [11-12]. To approach the industrial condition, rapid compression test has been employed by Kapranos [12], Liu [13] and Yurko [8]. This technique provides data on the viscosity response of the semisolid slurry under a rapid share change (i.e. a transient condition). The rheological behavior of the semisolid slurry is a 
function of the microstructural feature (e.g. grain morphology and size). The modification on the semisolid microstructure through the grain refinement might improve the rheological properties.

The objective of the present work was to process semisolid 7075 slurries using SEED rheocasting process and to assess the rheological properties at different process conditions. The effects of swirling frequency and grain refinement on the semisolid microstructure and rheoformability were evaluated. The deformation behavior and rheological properties of semisolid 7075 alloys were investigated by the rapid compression test.

\section{Experimental procedure}

The SEED rheocasting process [7] was used to produce AA7075 semisolid slurries with the following chemical composition (wt.\%): $\mathrm{Zn} \mathrm{5.7,} \mathrm{Mg}$ 3.0, $\mathrm{Cu}$ 1.6, Si 0.4, Mn 0.3 and Fe 0.4. The liquid metal was batched in an electrical resistance furnace. In some tests, the alloy was grainrefined with Al-5\%Ti-1\%B master alloy. The pouring temperature was $750{ }^{\circ} \mathrm{C}$. After the liquid alloy was poured into a metallic mold, the mechanical stirring (swirling) was applied at different frequencies of 120, 180 and 210 RPM. The dimension of the semisolid slurries was $90 \mathrm{~mm}$ in diameter and $150 \mathrm{~mm}$ in height. When the predetermined temperature was achieved, the swirling was stopped and the semisolid slurry was demolded. The rheological properties of semisolid slurries were studied by a parallel plate compression viscometer [14]. After the semisolid slurry was demolded, the slurry was transferred to the viscometer, in which the temperature was set the same as the predetermined processing temperature. Immediately, the upper plate with a weight of $36 \mathrm{Kg}$ was released and fell down under the gravity. As a result, the upper plate rapidly compressed the semisolid slurry. By using a displacement transducer $(0-255 \mathrm{~mm})$, the motion of the upper plate was monitored.

Differential scanning calorimeter (DSC) analysis was performed to determine the solidus and liquidus temperatures of the experimental 7050 alloy. The solid fraction (fs) of 7050 alloy as a function of temperature was calculated using the method [15] based on DSC results and is shown in Figure 1. The semisolid forming of metallic alloys majorly takes place at solid fractions between 0.4-0.6 [10]. Accordingly, all tests were conducted at the temperatures between $610-622{ }^{\circ} \mathrm{C}$ corresponding to a solid fraction range of 0.40.6. At higher processing temperatures the semisolid slurry did not stand its own weight to enable performing any compression test.

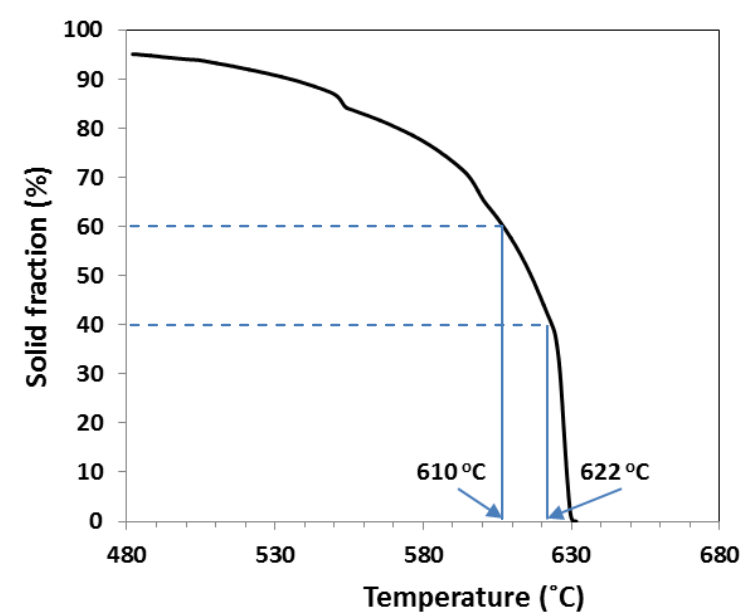

Fig. 1 Solid fraction vs temperature curve for 7075 alloy.

\section{Results and discussion}

Microstructural evolution after SEED processing and grain refinement. Figure 2 shows asquenched microstructures of semisolid slurries at different swirling frequencies and processing temperatures. It can be clearly seen that at low swirling frequency of 120 RPM, the semisolid microstructure consists of large irregular dendritic grains regardless of the processing temperatures. By increasing the stirring frequency to 180 RPM, the grains size sharply reduces and their morphology significantly improves and changes to rosette-like ones. Increase in the frequency from 120 to 180 RPM results in breaking the dendritic arms, leading to finer grain with improved globularity [16]. However, further increase in the frequency to 210 RPM has a limited effect on the grain morphology and size. It is worth mentioning that the homogenous globular grains is hardly 
achieved by only altering the SEED parameters for the 7075 alloy, and further modification of the microstructure is required.

Figure 3 shows the effect of grain refinement on the grain morphology and size after SEED processing for different swirling frequencies exemplary at $616{ }^{\circ} \mathrm{C}(0.50 \mathrm{fs})$. Micrographs of the 7075 base alloy at $616{ }^{\circ} \mathrm{C}$ can be found in Fig. 2 for comparison. It can be clearly seen that by addition of grain refiner $(0.03 \% \mathrm{Ti})$, dendritic and rosette-like grains of 7075 base alloy are considerably transformed to more globular grains. When the level of grain refiner is further increased $(0.06 \% \mathrm{Ti})$, it results in fine grains and fully globular morphology. For rapid compression tests, 7075 alloy with $0.03 \% \mathrm{Ti}$ is used since the semisolid slurry microstructure is acceptable with an average grain size less than $100 \mu \mathrm{m}$ and globular morphology [10].

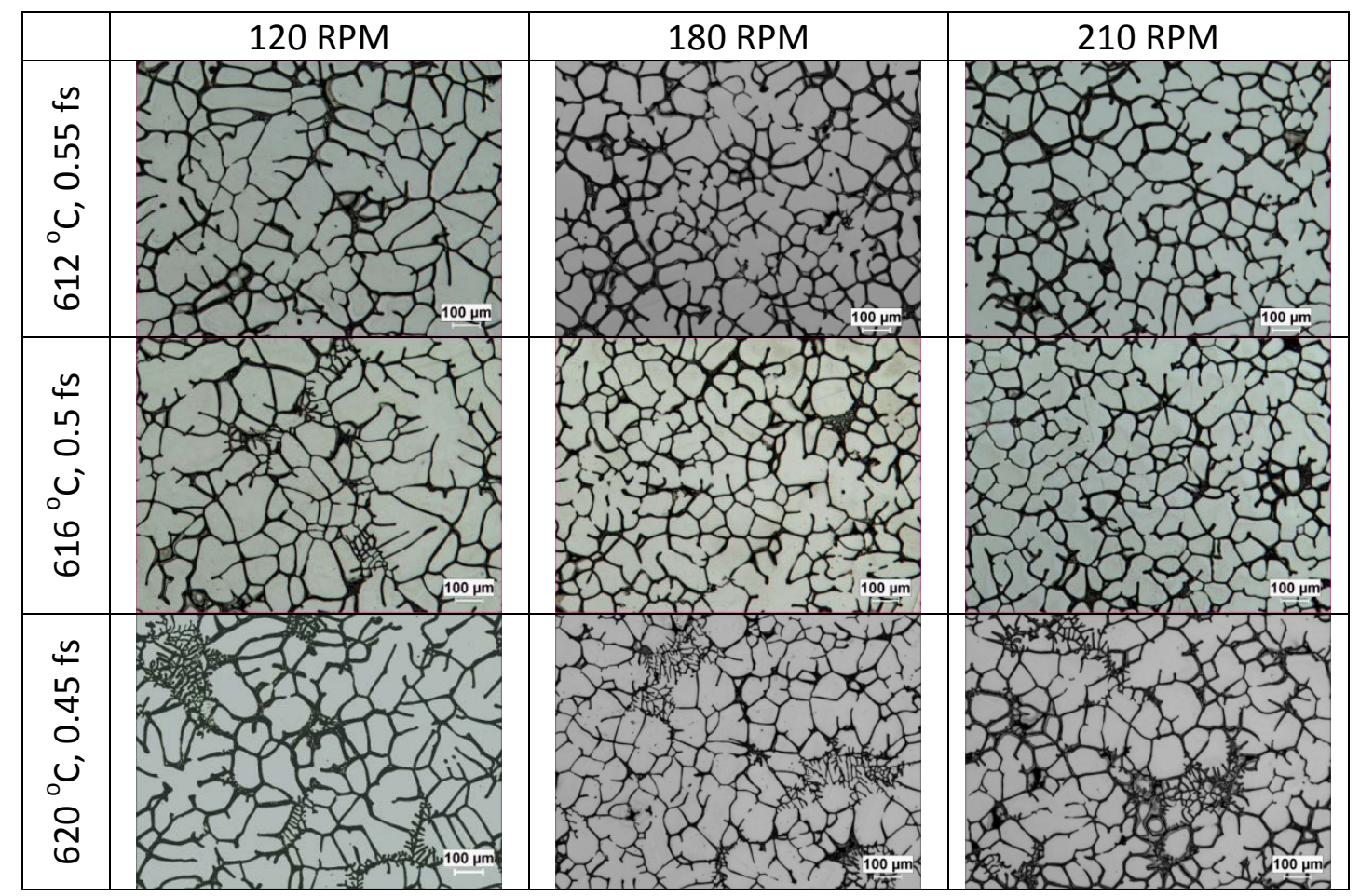

Fig. 2 Effect of swirling frequency on the semisolid microstructure of the 7075 base alloy at different processing temperatures.

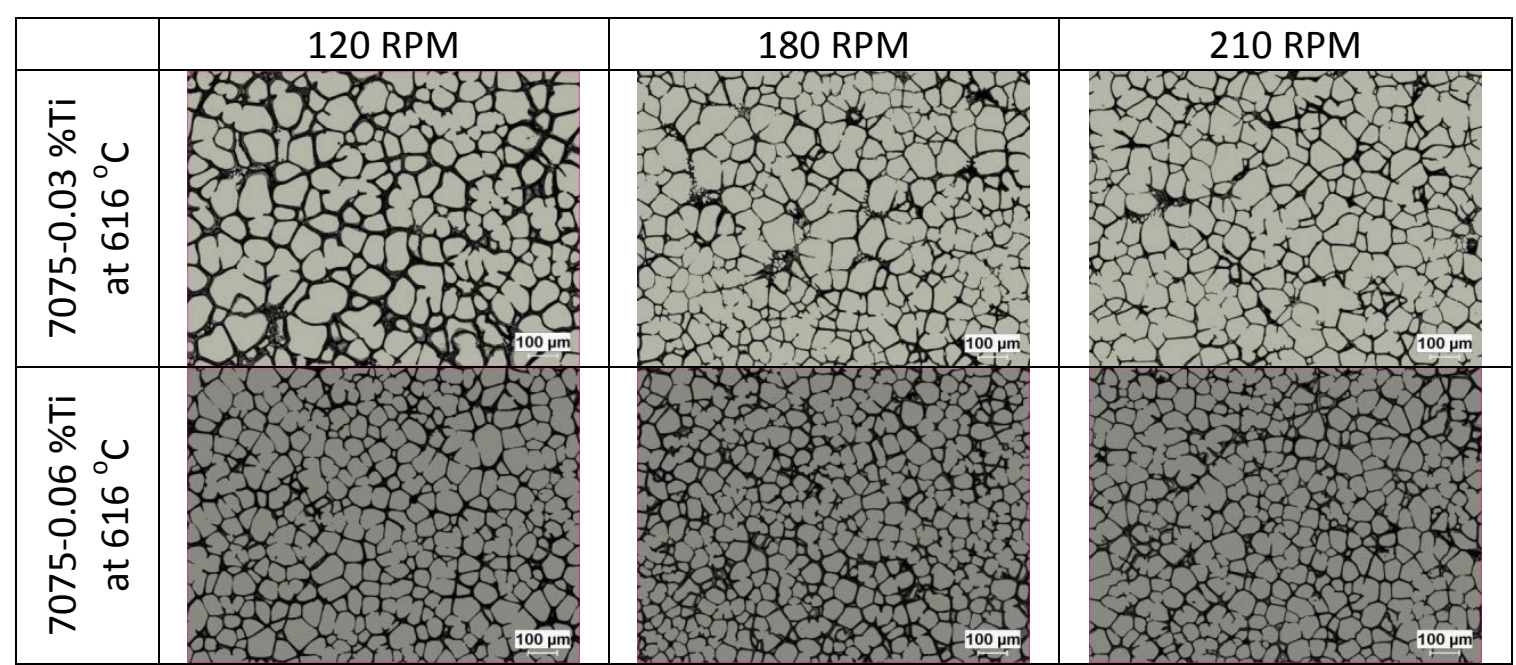

Fig. 3 Effect of grain refinement $\left(\mathrm{TiB}_{2}\right)$ on the semisolid microstructure at $616{ }^{\circ} \mathrm{C}(0.5 \mathrm{fs})$ with different swirling frequencies. 
Deformation behavior of semisolid slurries. Figure 4 gives an overview of the compressed billets at different processing temperatures for 7075 base and 7075-0.03\%Ti alloys. For 7075 base alloy, the deformation is only obtained at a narrow temperature range of $618-622{ }^{\circ} \mathrm{C}(0.42-0.48 \mathrm{fs})$. Below $618{ }^{\circ} \mathrm{C}$ (fs $>0.48$ ), the slurries of 7075 base alloy can hardly be deformed. For 7075-0.03\% Ti alloy, a full deformation takes place at a wide temperature range of $612-622^{\circ} \mathrm{C}(0.42-0.55 \mathrm{fs})$. This clearly reflects the effect of semisolid microstructure (e.g. grains morphology and size) on the deformation behavior for semisolid 7075 wrought alloy.

The normalized height reduction $\left(\mathrm{h} / \mathrm{h}_{0}, \mathrm{~h}=\right.$ instantaneous height of billet and $\mathrm{h}_{0}=$ initial height of billet) as function of compression time is shown in Figure 5. The results show that for 7075 base alloy, only a slight change in the processing temperature (one or two degrees) makes a significant difference in its response to shearing during rapid compression. A reasonable response to shearing occurs only between 619 and $622{ }^{\circ} \mathrm{C}(0.42-0.46 \mathrm{fs})$. In the contrast, for 7075-0.03\% $\mathrm{Ti}$ alloy, the response of the semisolid slurries appears to be identical in a wide temperature range of $614-622{ }^{\circ} \mathrm{C}$ (0.42-0.53 fs). The rapid compression test represents the applied shear on the slurry during die filling of the industrial semisolid forming process in the transient condition [11]. The 7075-0.03\% Ti alloy exhibits a consistent response to shearing in a wider fs range, resulting in more robust production and more consistent quality during semisolid casting compared to the 7075 base alloy.

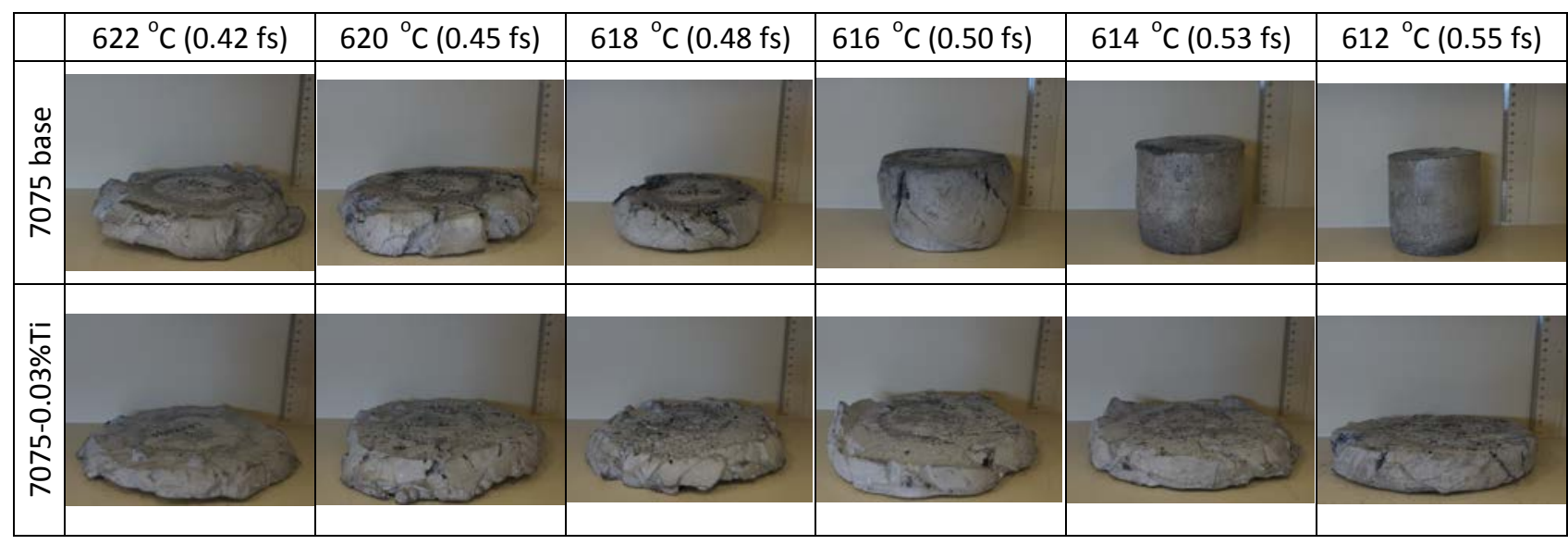

Fig. 4 Macrographs of compressed slurries for 7075 base and 7075-0.03Ti alloys at different processing temperatures.

(a)

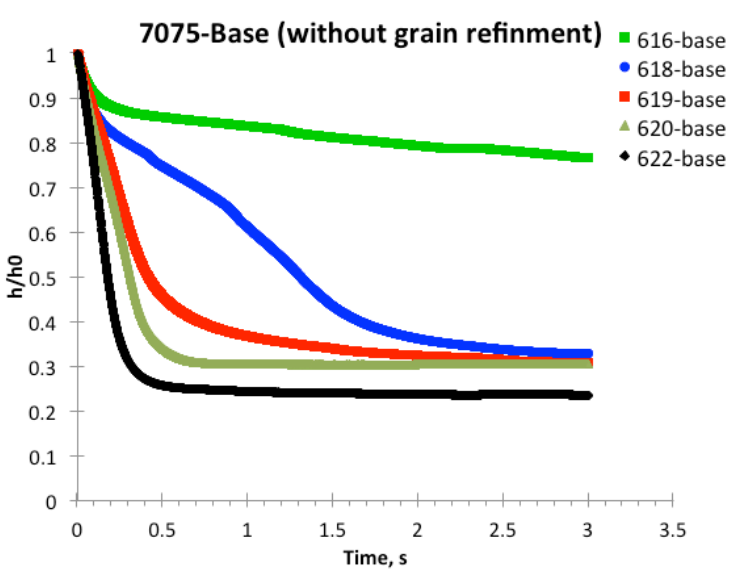

(b)

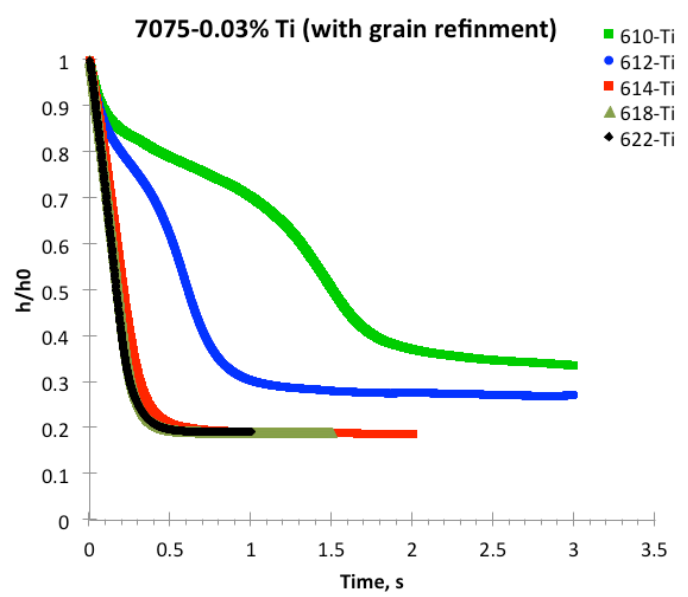

Fig. 5 Normalized height reductions $\left(\mathrm{h} / \mathrm{h}_{0}\right)$ of SEED processed $\% / \mathrm{h}$ slurries as a tunction of time under rapid compression for different temperatures.

Rheological properties. By using the method in Ref [8], assuming a Newtonian fluid, the viscosity of the semisolid billets under the compression test can be calculated by Eq. 1 and the average shear rate can be obtained by Eq. 2: 


$$
F=\frac{-3 \mu V^{2}}{2 \pi h^{5}}\left(\frac{d h}{d t}\right)
$$

$$
\gamma^{\prime}=\frac{R}{2 h^{2}} \frac{d h}{d t}
$$

where $\mathrm{F}=$ the applied force on the semisolid slurry, $\mathrm{V}=$ volume of the semisolid slurry, $\mu=$ viscosity, $\mathrm{h}=$ the instantaneous height of the billet and $\mathrm{t}=$ time. In the Eq. $2, \gamma^{\prime}=$ shear rate and $\mathrm{R}=$ maximum radial position of sample.

By considering that the force on the semisolid slurry was applied through the gravity of the weight (36 Kg) and substituting the measured $\mathrm{h}$ in the compression test and the calculated $\mathrm{dh} / \mathrm{dt}$, the viscosity and shear rate values can be calculated. Figure 6(a) shows a typical plot of viscosity vs shear rate as a function of time for $7050-0.03 \% \mathrm{Ti}$ alloys at $622{ }^{\circ} \mathrm{C}(0.42 \mathrm{fs})$. The data are plotted in the transient state (less than 1 second) as the deformation was completed around 0.7 second. The viscosity decreases rapidly to a minimum within 0.2 second and remains at very low level, while the shear rate increases sharply to a maximum and drops back to a minimum till the end of deformation. The viscosity vs shear rate curve is shown in Fig. 4(b) and it can be characterized in two parts: (1) the viscosity continuously decreases with increasing the share rate to reach the maximum shear rate, and followed by (2) a moderate recovery with decreasing the shear rate.

The grain refinement has an important impact on the rheological properties and rheofomability. Figure 7 compares the viscosity evolution as a function of shear rate for two alloys, the base and refined alloys, at different processing temperatures (solid fractions). At a given solid fraction, the achievable maximum shear rate in the base alloy is much lower than the grain-refined alloy while the measured viscosity of the base alloy is higher than that of the grain-refined alloy. It can be seen that the achievable maximum shear rate in the base alloy decreases significantly with increasing solid fraction and the relined V-shape viscosity curve shrinks quickly toward the low shear rate and high viscosity corner. It is apparent that only at the processing temperature range of $622-620{ }^{\circ} \mathrm{C}$ (0.42-0.45 fs), the viscosity of the base alloy retains a relatively low level (Fig. 7a and b) and thus having a reasonable rheoformabilty. At higher fs $(>0.45)$, due to very high viscosity, the base alloy may lose its rheoformabilty (Fig. 7c). On the contrast, the grain-refined alloy achieves a constantly high level of the maximum shear rate in a wider range of the processing temperatures from 622 to $614{ }^{\circ} \mathrm{C}$ (0.42-0.53 fs) and their corresponding viscosity values always remain at a low level, indicating an excellent rheoformabilty at the fs range of 0.4-0.53.

(a)

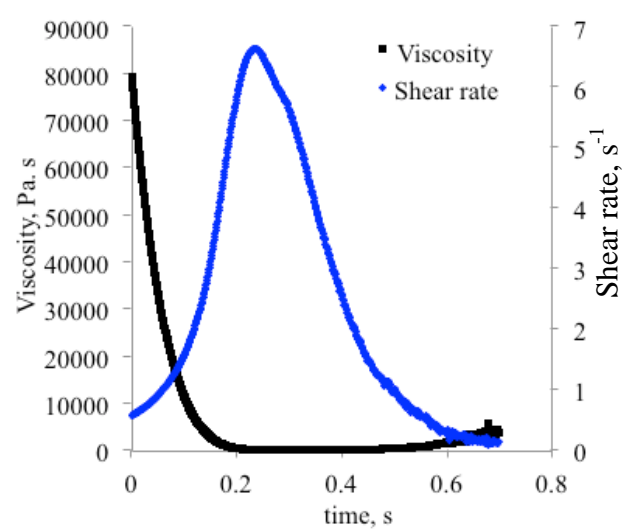

(b)

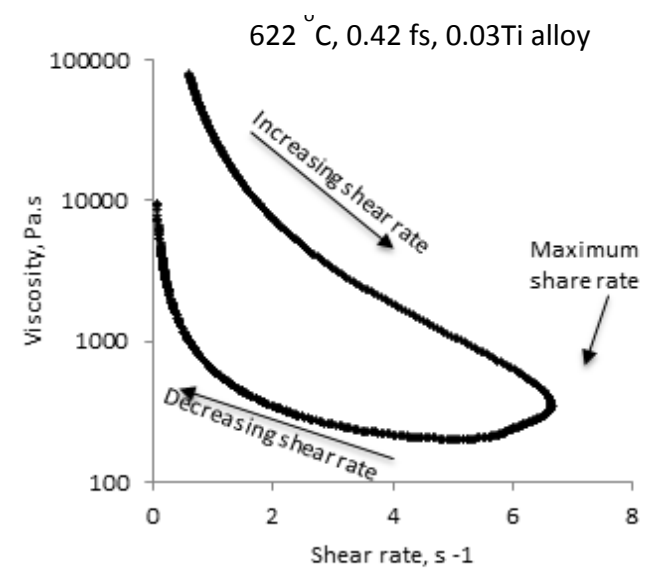

Fig. 6 (a) Viscosity and shear rate as a function of time for $7075-0.03 \% \mathrm{Ti}$ at $622{ }^{\circ} \mathrm{C}(0.42 \mathrm{fs})$ and (b) viscosity as a function of shear rate.

\section{Conclusions}

1. The optimum swirling frequency of SEED process for 7075 aluminum alloy was obtained at 180 RPM. However, a fine and fully globular grain structure was difficult to achieve by only adjusting SEED processing parameters. 
2. By adding $0.03 \%$ and $0.06 \% \mathrm{Ti}$ in the form of $\mathrm{Al}-5 \% \mathrm{Ti}-1 \% \mathrm{~B}$, a significant improvement in the grain morphology and size with a fully globular structure was obtained.

3. Deformation behavior of semisolid 7075 alloys was evaluated by a rapid compression test. The 7075 base alloy exhibited a narrow window of solid fractions (0.42-0.463 fs) that the semisolid slurry can be deformed. On the contrast, the 7075-0.03\% Ti alloy can be easily deformed at a wider range of solid fractions (0.42-0.53 fs).

4. The rheological properties (viscosity vs shear rate) of 7075 base alloy showed a very high dependency on the solid fraction. The grain refinement (7075-0.03\%Ti alloy) greatly improved the viscosity and rheoformability in a wider range of solid fractions compared to the base alloy.

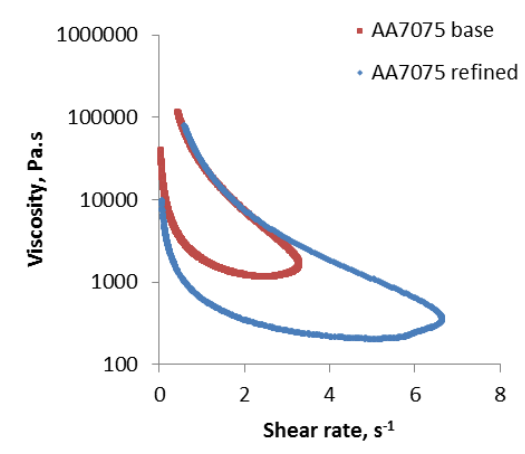

(a) $622{ }^{\circ} \mathrm{C}, 0.42 \mathrm{fs}$

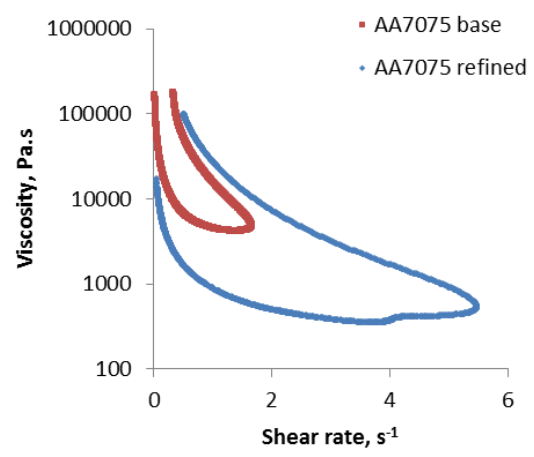

(b) $620{ }^{\circ} \mathrm{C}, 0.45 \mathrm{fs}$

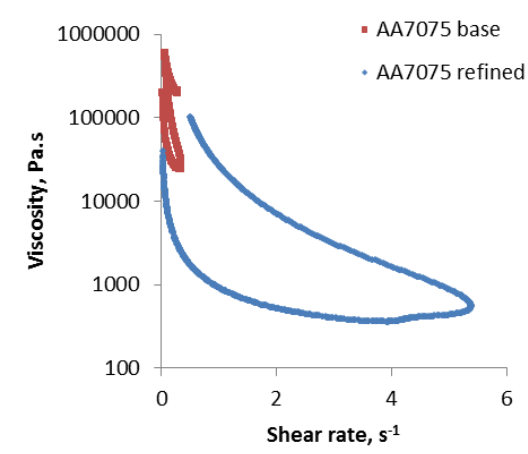

(c) $618{ }^{\circ} \mathrm{C}, 0.48 \mathrm{fs}$

Fig. 7 Comparison of viscosity vs shear rate curves of 7075 base and $7075-0.03 \%$ Ti alloys with various processing temperatures (solid fractions): (a) $622{ }^{\circ} \mathrm{C}, 0.42 \mathrm{fs}$, (b) $620^{\circ} \mathrm{C}, 0.45 \mathrm{fs}$, (c) $618{ }^{\circ} \mathrm{C}$, $0.48 \mathrm{fs}$.

Acknowledgement. The authors would like to acknowledge the financial support from the Natural Sciences and Engineering Research Council of Canada (NSERC) and the Société des Technologies de l'Aluminium du Saguenay Inc. (STAS), through the NSERC Industry Research Chair in Metallurgy of Aluminum Transformation at the University of Quebec at Chicoutimi.

\section{References}

[1] S. Chayong, H. V. Atkinson, and P. Kapranos, Mater. Sci. Eng. A, 390 (2005) 3-12.

[2] A. Bolouri and C. G. Kang, Renew. Energy, 71 (2014) 616-628.

[3] A. Bolouri, M. Shahmiri, and C. G. Kang, J. Mater. Sci., 47(2012) 3544-3553.

[4] J. Langlais, N. Andrade, A. Lemieux, X. G. Chen, and L. Bucher, Solid State Phenom., 141143 (2008) 511-516.

[5] U. A. Curle, Trans. Nonfer. Met. Soc. China (English Ed.), 20 (2010) 1719-1724.

[6] I.-G. Chung, A. Bolouri, and C. Kang, Int. J. Adv. Manuf. Technol., 58 (2011) 237-245.

[7] P. Côté, M. E. Larouche and X. G. Chen, Solid State Pheno., 192-193 (2013) 373-378.

[8] J. Yurko and M. C. Flemings, Metall. Mater. Trans. A, 33 (2002) 2737-2746.

[9] E. J. Zoqui and L. V. Torres, Mater. Res., 13 (2010) 305-318.

[10] H. V. Atkinson, Comprehensive Materials Processing. Elsevier, 2014.

[11] D. Kirkwood and P. Ward, Steel Res., 75 (2004) 519-524.

[12] P. Kapranos, T. Y. Liu, H. V. Atkinson, and D. H. Kirkwood, J. Mater. Process. Technol., 111 (2001) 31-36.

[13] H. V. A. T.Y. Liu P. Kapranos, D.H. Kirkwood and S.C. Hogg, Metall. Mater. Trans. A, 34 (2003) 1545-1554.

[14] M. Tebib, F. Ajersch and X.-G. Chen, Solid State Pheno., 192-193 (2013) 323-328.

[15] Y. Birol, J. Alloys Comp., 486 (2009) 173-177.

[16] I.-G. Chung, A. Bolouri, and C. Kang, Int. J. Adv. Manuf. Technol., 58 (2011) 237-245. 